\title{
Blastic Plasmacytoid Dendritic Cell Neoplasm With Leukemic Progression
}

\author{
Choladda V. Curry ${ }^{\mathrm{a}}$, Sergej N. Konoplev ${ }^{\mathrm{b}}$, Carlos Torres-Cabala ${ }^{\mathrm{c}, \mathrm{d}}$, Amin Alousi ${ }^{\mathrm{e}}$, \\ Madeleine Duvic ${ }^{d}$, Jonathan L. Curry ${ }^{\mathrm{c}, \mathrm{d}, \mathrm{f}}$
}

\begin{abstract}
Blastic plasmacytoid dendritic cell neoplasm (BPDN), previously described as blastic NK cell lymphoma and CD4+/CD56+ hematodermic neoplasm is an aggressive hematologic malignancy with poor prognosis. We report a patient with BPDN who developed multiple recurrences and eventually leukemic progression. The patient died of disease 31 months after initial diagnosis. Long term survival for BPDN is poor despite multiple regimens of chemotherapy and bone marrow stem cell transplant.
\end{abstract}

Keywords: Blastic Plasmacytoid dendritic cell neoplasm; Blastic NK cell lymphoma; CD4+/CD56+ hematodermic neoplasm; Leukemia; Stem cell transplant

\section{Case Report}

A 66-year-old male presented with a $3 \mathrm{~cm}$ elevated, violaceous nodule on the back for 3 months duration without resolution. Biopsy examination of the nodule demonstrated

Manuscript accepted for publication July 27, 2012

${ }^{a}$ Department of Pathology, Baylor College of Medicine and Texas Children's Hospital, Houston, Texas, U.S.A.

${ }^{\mathrm{b}}$ Departments of Hematopathology, the University of Texas MD Anderson Cancer Center, Houston, Texas, U.S.A.

${ }^{c}$ Departments of Pathology, the University of Texas MD Anderson Cancer Center, Houston, Texas, U.S.A.

${ }^{\mathrm{d}}$ Departments of Dermatology, the University of Texas MD Anderson Cancer Center, Houston, Texas, U.S.A.

e Departments of Stem Cell Transplantation, the University of Texas MD Anderson Cancer Center, Houston, Texas, U.S.A.

${ }^{\mathrm{f}}$ Corresponding author: Jonathan L. Curry, Department of Pathology, the University of Texas MD Anderson Cancer Center, Houston, Texas,

U.S.A. Email: jlcurry@mdanderson.org

doi: http://dx.doi.org/10.4021/jmc829w a dense hematolymphoid infiltrate composed of blastic appearing neoplastic cells involving the dermis and superficial portion of the subcutaneous tissue. The epidermis was not involved and was separated by a narrow Grenz zone. The neoplastic cells were reactive for CD4, CD56 and CD45RA and negative for CD20, CD3, CD8, TdT, CD34, and CD117. A diagnosis of cutaneous blastic plasmacytoid dendritic cell neoplasm (BPDCN) was rendered, and the nodule was excised. Staging studies with CT scan and PET/CT scan showed neither lymphadenopathy nor FDG-avid lesions. A month later, the patient continued to develop multiple purple to brown, bruise like macules and papules on his chest, back, extremities and face (Fig. 1A). The skin punch biopsy of right upper back shows a monotonous infiltrate of neoplastic cells of similar cytomorphology to the previous biopsies, primarily distributed in a perivascular and periadnexal pattern (Fig. 1B-C). Immunohistochemically (IHC), neoplastic cells were positive for CD4, CD56, CD123, and TCL-1 (Fig. 1DF), and are negative for CD3, CD8 and CD20.

The patient was subsequently treated with four cycles of hyper CVAD alternating with methotrexate and cytarabine which resulted in reduction and disappearance of his skin lesions. The patient remained in remission. Nineteen months after initial presentation, PET scan demonstrated a new hypermetabolic cutaneous mass on the left lower leg and biopsy confirmed recurrence of disease. Bilateral bone marrow biopsy was negative for neoplasm. Patient was treated with six cycles of pralatrexate and during his second complete remission underwent autologous peripheral blood stem cell transplant with BEAM (carmustine (BCNU), etoposide, Ara$\mathrm{C}$ (cytarabine), and melphalan) conditioning. He remained without evidence of cutaneous disease at 160 days status post autologous stem cell transplant when he developed pancytopenia which prompted bone marrow biopsy that demonstrated progression to acute leukemia with $77 \%$ blasts along with circulating blasts in peripheral blood at 30 months since initial diagnosis of BPDN (Fig. 1G, H). By flow cytometric analysis, blasts were positive for CD4, CD7 (dim), CD56, CD33, CD117, HLA-DR, and TdT (partial) and negative for $\mathrm{CD} 2, \mathrm{CD} 3, \mathrm{CD} 5, \mathrm{CD} 8, \mathrm{CD} 34$, and myeloperoxidase. Leukemic cells were positive for CD123 by IHC (Fig. 1I). The patient died of disease 31 months after initial diagnosis. 


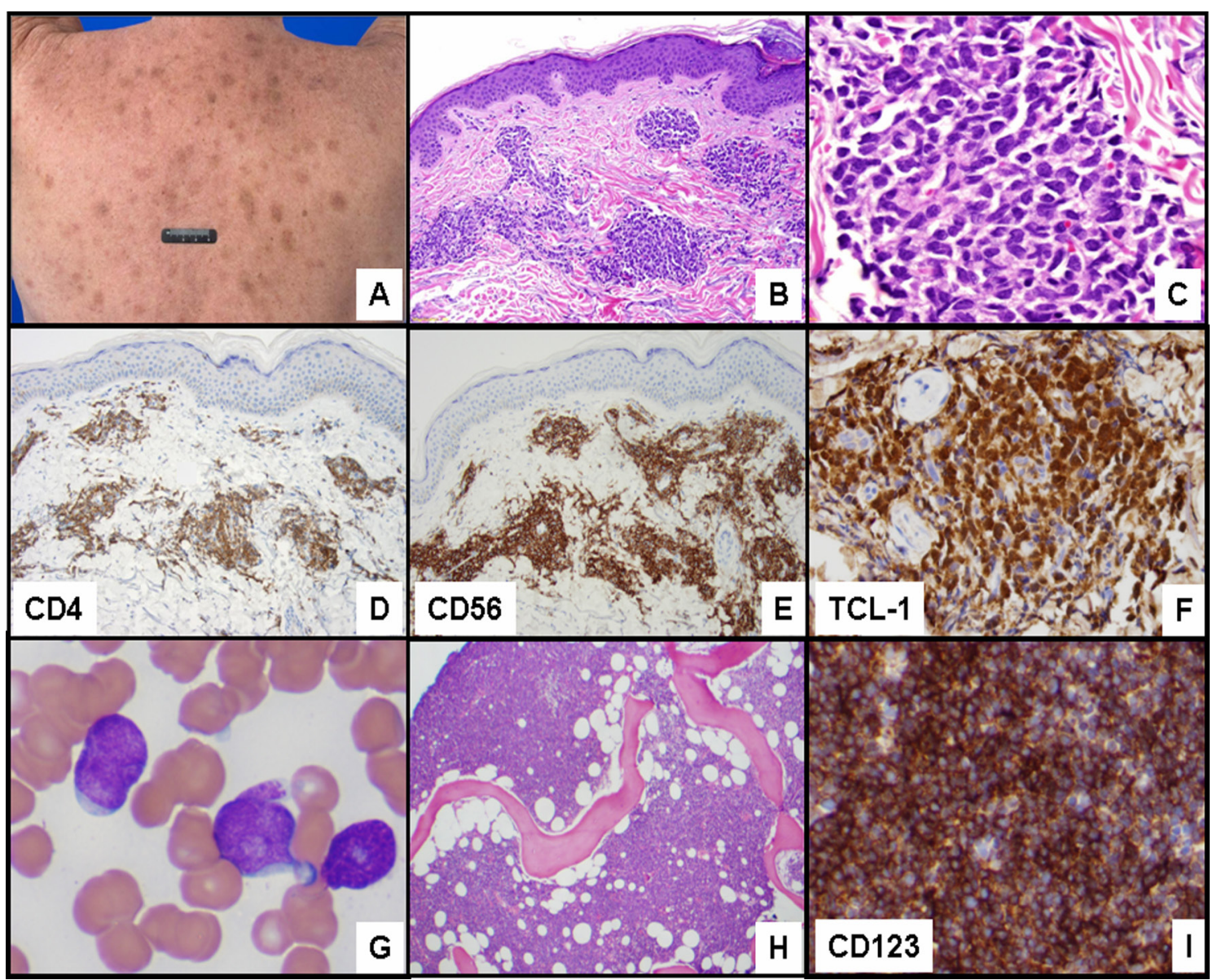

Figure 1. (A) Multiple purple to brown macules and papules on the back. (B) Skin biopsy with neoplastic cells in the dermis distributed in a perivascular and periadnexal pattern (hematoxylin-eosin (H \& E) stain, original magnification $100 \mathrm{x})$. (C) Monotonous infiltrate of blastic appearing neoplastic cells in the dermis (H \& E stain, original magnification, $400 \mathrm{x}$ ) positive for (D) CD4 (original magnification $100 \mathrm{x}$ ), (E) CD56 (original magnification $100 \mathrm{x}$, and (F) TCL-1 (original magnification $200 \mathrm{x}$ ). (G) Peripheral blood smear with circulating blasts (Wright Giemsa, original magnification 1,000 x), $(H)$ and bone marrow with acute leukemia $(H$ \& $E$, original magnification $40 \mathrm{x}$ ). (I) Leukemic cells positive for CD123 (original magnification $200 \mathrm{x}$ ).

\section{Discussion}

Blastic plasmacytoid dendritic cell neoplasm, previously described as blastic NK cell lymphoma and CD4+/CD56+ hematodermic neoplasm is an aggressive hematologic malignancy with poor prognosis [1-3]. The CD4+/CD56+ neoplastic cells demonstrate differentiation towards the plasmacytoid type 2 dendritic cell (DC2) and therefore also express CD123 and lymphoid proto-oncogene TCL1 [4]. One third of the cases are TdT positive [1]. Lesions may be localized or present as generalized tumors and plaques with bruise-like violaceous appearance. Bone marrow involvement is known to occur often with leukemic progression of advanced or relapsed disease $[5,6]$. Response to systemic chemotherapy with short period of remissions followed by recurrence is typical. Long term survival is dismal with conventional therapy and bone marrow stem cell transplantation should be considered as therapeutic option $[7,8]$.

\section{Grant Support}

Not applicable.

\section{References}

1. Facchetti F JD, Petrella T. Blastic plasmacytoid dendrtic cell neoplasm. In: Swerdlow SH CE, Harris NL, et. al., ed. WHO Classification of Tumours of Haematopoietic and Lymphoid Tissues: LYON: IARC Press; 2008:145147

2. Cota C, Vale E, Viana I, Requena L, Ferrara G, Anemona $\mathrm{L}$, Metze D, et al. Cutaneous manifestations of blastic plasmacytoid dendritic cell neoplasm-morphologic and phenotypic variability in a series of 33 patients. Am J Surg Pathol. 2010;34(1):75-87.

3. Petrella T, Bagot M, Willemze R, Beylot-Barry M, Ver- 
gier B, Delaunay M, Meijer CJ, et al. Blastic NK-cell lymphomas (agranular CD4+CD56+ hematodermic neoplasms): a review. Am J Clin Pathol. 2005;123(5):662-675.

4. Herling M, Teitell MA, Shen RR, Medeiros LJ, Jones D. TCL1 expression in plasmacytoid dendritic cells (DC2s) and the related CD4+ CD56+ blastic tumors of skin. Blood. 2003;101(12):5007-5009.

5. Chaperot L, Bendriss N, Manches O, Gressin R, Maynadie M, Trimoreau F, Orfeuvre H, et al. Identification of a leukemic counterpart of the plasmacytoid dendritic cells. Blood. 2001;97(10):3210-3217.

6. Jegalian AG, Facchetti F, Jaffe ES. Plasmacytoid den- dritic cells: physiologic roles and pathologic states. Adv Anat Pathol. 2009;16(6):392-404

7. Krishnan S, Tan D, Hwang WY. Treatment of blastic plasmacytoid dendritic cell neoplasms with cord blood transplants. Clin Adv Hematol Oncol. 2011;9(7):569570.

8. Male HJ, Davis MB, McGuirk JP, Abhyankar S, Aljitawi OS, Zhang D, Ganguly S. Blastic plasmacytoid dendritic cell neoplasm should be treated with acute leukemia type induction chemotherapy and allogeneic stem cell transplantation in first remission. Int $\mathrm{J}$ Hematol. 2010;92(2):398-400. 